\title{
Ordering and Shipping Strategies of Materials for Company
}

\author{
Yiyang LYU ${ }^{\mathrm{a}}$, Haonan $\mathrm{XU}^{\mathrm{b}}$, Kangnong $\mathrm{HU}^{\mathrm{b}}$ and Biao $\mathrm{ZHANG}{ }^{\mathrm{a}}{ }^{1}$ \\ a School of Material Science and Engineering, Xiangtan University, Xiangtan, China \\ ${ }^{\mathrm{b}}$ School of Mathematics and Computational Science, Xiangtan University, Xiangtan, \\ China
}

\begin{abstract}
Ordering and shipping of raw materials is a very important part of a company's production operations. How to properly arrange the scheme to minimize the transportation and ordering cost is a great concern for enterprises. In this paper, two related models are proposed for the $\mathrm{C}$ problem of the Contemporary Undergraduate Mathematical Contest in Modeling: a supplier evaluation model based on Entropy Weight Method, TOPSIS Algorithm and other methods, and an ordering and transportation target planning model based on seasonality analysis and other methods. The former establishes seven supplier importance evaluation indexes based on quantitative analysis from two perspectives of supplier supply capability and business enterprise closeness, analyzes the influence weights of the seven indexes by Entropy Weight Method, and uses TOPSIS Algorithm to calculate the rating ranking of each supplier. The latter is based on the contribution rate of goods, material selection tendency, and corporate interest as the primary factors for enterprises to determine the scheme under different circumstances, and the future supply and demand is predicted through seasonal analysis to establish a target planning model to determine the shopping scheme.
\end{abstract}

Keywords. TOPSIS Algorithm;seasonality analysis;Entropy Weight Method;step search method.

\section{Introduction}

Ordering and shipping of materials is an important strategic decision that every business needs to make. The establishment of a trans-shipment solution requires the consideration of a variety of factors, and scientific and comprehensive consideration of some factors can bring more benefits to the enterprise. We conducted a study of this problem based on data from the enterprise in question, hoping to explore the selection of material ordering and shipping options through a study of the enterprise. The weekly capacity of the enterprise is $2.82 \times 10^{5} \mathrm{~m}^{3}$, and each production $1 \mathrm{~m}^{3}$ products need to spend A raw materials $0.6 \mathrm{~m}^{3}$, or B raw materials $0.66 \mathrm{~m}^{3}$, or $\mathrm{C}$ raw materials $0.72 \mathrm{~m}^{3}$. At the same time, the enterprise to ensure stable production needs, will try to ensure that the inventory is as adequate as possible, usually choose to acquire all the actual supply of raw materials from suppliers. In the actual delivery process, there is a loss of materials, and the weekly transportation value of each logistics provider is $6000 \mathrm{~m}^{3}$. At the same time, the order prices of raw materials of category $\mathrm{A}$ and $\mathrm{B}$ are $20 \%$ and $10 \%$ higher than those of

1 Corresponding Author, Biao ZHANG, School of Material Science and Engineering, Xiangtan University, Xiangtan, China; Email: xiaobiao_zhang@outlook.com. 
category C. In this paper we quantify and analyze the characteristics of the goods supplied by the suppliers, score the suppliers by entropy weight method, TOPSIS algorithm, and also consider a variety of situations to predict the supply and demand of the enterprise based on seasonal analysis, and determine the purchase and delivery plan of the enterprise.

\section{Supplier Evaluation Based on Supply Characteristics Analysis}

\subsection{Problem Analysis}

First of all, we quantify and analyze the importance of suppliers based on the supplier supply capacity and the closeness of business enterprises. Based on the analysis of supplier supply capacity, we can establish the supply satisfaction rate, total supply output, weekly maximum supply quantity, similar products competitiveness evaluation index; based on the analysis of supplier enterprise closeness, we establish the supplier cooperation degree, supply stability, the longest continuous supply days evaluation index. After determining the 7 evaluation indicators, we use the Entropy Weight Method to determine the weight of each indicator, and then based on TOPSIS Algorithm, we establish the comprehensive evaluation model of suppliers, and calculate the score of each supplier based on the distance between the principal component data and its corresponding maximum and minimum values.

\subsection{Quantitative Analysis of Supply Characteristics}

For all suppliers, we quantified and analyzed the importance of suppliers from two perspectives: supplier supply capability and business enterprise closeness, and selected seven indicators to reflect the importance of suppliers (table 1).

Table 1. Supplier indicators and explanation of indicators

\begin{tabular}{|c|c|c|}
\hline $\begin{array}{l}\text { Selection of } \\
\text { angles }\end{array}$ & Corresponding indicators & Explanation of indicators \\
\hline \multirow{4}{*}{$\begin{array}{l}\text { Suppliers } \\
\text { Supply } \\
\text { capacity }\end{array}$} & Supply satisfaction rate & $\begin{array}{l}\text { The supplier's supply quantity to meet the order quantity in } \\
\text { the past five years. }\end{array}$ \\
\hline & $\begin{array}{l}\text { Total supply of production } \\
\text { capacity }\end{array}$ & $\begin{array}{l}\text { The sum of the supplier's supply of the last five years of } \\
\text { capacity. }\end{array}$ \\
\hline & $\begin{array}{l}\text { Maximum weekly supply } \\
\text { quantity }\end{array}$ & Supplier's weekly maximum supply in the last five years. \\
\hline & $\begin{array}{l}\text { Competitiveness of similar } \\
\text { products }\end{array}$ & $\begin{array}{l}\text { Share of supply from a single supplier among multiple } \\
\text { suppliers in the same category. }\end{array}$ \\
\hline \multirow{3}{*}{$\begin{array}{c}\text { Business } \\
\text { Enterprise } \\
\text { Intimacy }\end{array}$} & Stability of supply & $\begin{array}{l}\text { The variance of } 10 \text { groups of semi-annual supply data of } \\
\text { each supplier. }\end{array}$ \\
\hline & Supplier cooperation degree & Number of supplier-company trade weeks in 5 years. \\
\hline & $\begin{array}{l}\text { Maximum number of } \\
\text { consecutive delivery days }\end{array}$ & $\begin{array}{l}\text { Maximum number of weeks of continuous supply of } \\
\text { materials to the enterprise by the supplier }\end{array}$ \\
\hline
\end{tabular}

\subsection{Supplier Importance Rating}

(1) Determination of indicator weights

After getting the 7 evaluation indicators, we analyzed the weight of the evaluation indicators for the dispersion degree of each indicator, and the greater the dispersion 
degree, we judged that the greater the influence weight of the indicator. Based on this, we use the Entropy Weight Method to determine the dispersion degree and get the weight of each indicator by calculating the entropy value of the information of the 7 evaluation indicators [1]. The specific steps are as follows.

Step. 1: Setting of data

The $m_{k}$ evaluation index of the importance of the first supplier among the supply satisfaction rate, total supply output, maximum weekly supply, competitiveness of similar products, cooperation of suppliers, stability of supply and the longest continuous supply days $k$.

Step. 2: Maximization of indicators

Among the seven indicators, we first maximize all of them. In this problem, we only need to maximize the supply stability again, and here we take the negative value of the original value and change it from a minimizing indicator to a maximizing indicator.

Step. 3: Standardization of indicators

Set $m_{k}^{\prime}$ as the standardized value of the first $k$ evaluation index, and calculate the formula as follows.

$$
m_{k}^{\prime}=\frac{m_{k}-\min \left(m_{k}\right)}{\max \left(m_{k}\right)-\min \left(m_{k}\right)}
$$

where $\max \left(m_{k}\right)$ is the maximum value $m_{k}$ in the array; $\min \left(m_{k}\right)$ is the minimum value in $m_{k}$ the array.

Here again we set to be the first $m_{k i}^{\prime} m_{k}^{\prime} i$ value in the array.

Step. 4: Calculation of information entropy

Let $H_{k}$ be the information entropy of the data of the first $k$ evaluation index, and calculate the formula as follows.

$$
H_{k}=-\frac{1}{\ln 402} \sum_{i=1}^{402} p_{k i} \ln p_{k i}
$$

Among them

$$
p_{k i}=\frac{m_{k i}^{\prime}}{\sum_{i=1}^{402} m_{k i}^{\prime}}
$$

Step. 5: Calculation of index weights

The impact weight of the first $k$ evaluation indicator is set $w_{k}$ as the following formula.

$$
w_{k}=\frac{1-H_{k}}{7-\sum_{k=1}^{7} H_{k}}
$$


The above steps were calculated by MATLAB software and the following results were obtained in table 2.

Table 2. Corresponding weights of each index

\begin{tabular}{cccc}
\hline Supply satisfaction rate & Total supply production & $\begin{array}{c}\text { Maximum weekly } \\
\text { supply quantity }\end{array}$ & $\begin{array}{c}\text { Competitiveness of } \\
\text { similar products }\end{array}$ \\
\hline $1.50 \%$ & $24.02 \%$ & $28.52 \%$ & $23.97 \%$ \\
Stability of supply & $\begin{array}{c}\text { Supplier cooperation } \\
\text { degree }\end{array}$ & $\begin{array}{c}\text { Number of days of } \\
\text { continuous supply }\end{array}$ \\
\hline $0.10 \%$ & $5.26 \%$ & $16.62 \%$ & \\
\hline
\end{tabular}

(2) Integrated scoring solution

After obtaining the weights of each evaluation index, we use TOPSIS Algorithm to establish the supplier importance evaluation model. We multiply each index weight by the standardized index value to get the weight index value, calculate the supplier score based on the distance between the weight index value data and the best value and the worst value, and finally select the top 50 rated suppliers. The specific steps are as follows.

Step. 1: Setting of data

$m_{k}^{\prime}$ is the entropy-weighted standardized value of the first $k$ evaluation index.

$w_{k}$ is the impact weight of the first $k$ evaluation indicator.

Step. 2: Calculation of weight index value

Set $m_{k}^{\prime \prime}$ as the first $k$ evaluation index weight indicator value, the calculation formula is as follows.

$$
m_{k}^{\prime \prime}=m_{k}^{\prime} \times w_{k}
$$

Here again we set to be the first $m_{k i}^{\prime \prime} m_{k}^{\prime \prime} i$ value in the array.

Step. 3: Calculation of the closeness of the superiority and inferiority values

Let the degree of approximation of the superior $d_{k}^{+}$value be, and the degree of approximation of the inferior value be $d_{k}^{-}$, calculated as follows.

$$
\begin{aligned}
d_{i}^{+} & =\sqrt{\sum_{k=1}^{7}\left(m_{k i}^{\prime \prime}-\max \left(m_{k}^{\prime \prime}\right)\right)^{2}} \\
d_{i}^{-} & =\sqrt{\sum_{k=1}^{7}\left(m_{k i}^{\prime \prime}-\min \left(m_{k}^{\prime \prime}\right)\right)^{2}}
\end{aligned}
$$

where $\max \left(m_{k}^{\prime \prime}\right)$ is the maximum value $m_{k}^{\prime \prime}$ in the array; $\min \left(m_{k}^{\prime \prime}\right)$ is the minimum value in $m_{k}^{\prime \prime}$ the array.

Step. 4: Supplier rating value calculation

Let the rating value of the first $i$ supplier be $C_{i}$, calculated by the following formula. 


$$
C_{i}=\frac{d_{i}^{-}}{d_{i}^{+}+d_{i}^{-}}
$$

Step. 5: Scoring value percentage system

Let the percentage rating value of the first $i$ supplier be $C_{i}^{\prime}$, calculated as follows.

$$
C_{i}^{\prime}=100 \times \frac{C_{i}-\min \left(C_{i}\right)}{\max \left(C_{i}\right)-\min \left(C_{i}\right)}
$$

The above steps were calculated by MATLAB software and the ranking scores of each supplier are shown in the following table 3.

Table 3. Supplier vendor ranking score table

\begin{tabular}{ccc|ccc|ccc}
\hline Ranking & Supplier & Score & Ranking & Supplier & Score & Ranking & Supplier & Score \\
\hline 1 & 140 & 100.00 & 11 & 308 & 64.81 & 21 & 143 & 54.73 \\
2 & 151 & 87.43 & 12 & 282 & 64.02 & 22 & 194 & 54.47 \\
3 & 229 & 84.42 & 13 & 340 & 62.52 & 23 & 352 & 54.18 \\
4 & 348 & 82.84 & 14 & 275 & 62.10 & 24 & 284 & 50.67 \\
5 & 361 & 79.58 & 15 & 329 & 61.86 & 25 & 126 & 50.56 \\
6 & 108 & 77.55 & 16 & 131 & 58.68 & 26 & 247 & 50.50 \\
7 & 201 & 72.03 & 17 & 356 & 58.14 & 27 & 365 & 49.39 \\
8 & 374 & 69.08 & 18 & 268 & 57.32 & 28 & 31 & 49.37 \\
9 & 330 & 66.36 & 19 & 306 & 57.09 & 29 & 395 & 49.37 \\
10 & 139 & 65.67 & 20 & 307 & 55.04 & 30 & 40 & 48.79 \\
\hline
\end{tabular}

\section{The Best Shopping and Shipping Solution}

\subsection{Problem Analysis}

First, we determine the average supply quantity of the top 50 suppliers in case of supply demand of the company, and prioritize the suppliers based on the average supply quantity, the results show that at least 26 suppliers are selected to meet the production demand.

Then, we established the material ordering planning model with the minimum cost as the objective function, and at the same time, based on the analysis of 26 groups of suppliers' supply data in the past 5 years, we confirmed the constraints of the planning model: (1) with 24 weeks as one cycle and 10 cycles in 5 years, we found that the overall supply of suppliers has a strong cyclicality, and we made seasonal analysis and forecast based on the cyclicality of data to determine the future 24 weeks The total forecast value is used as the total order quantity for each week of 24 weeks; (2) there are maximum and minimum values of supply quantity for each supplier in the last 10 cycles, and considering the feasibility of the ordering scheme, the process of developing the ordering scheme for the next 24 weeks ensures that the order quantity is located in the extreme value range of the last 10 cycles; (3) each forwarder has limited transportation capacity, and usually, a single week supplier tries to choose one supplier in a single week. Based on this, we determine the maximum value of single supply quantity for each supplier in 
each future week to avoid the situation that too much raw material is prepared and cannot be shipped. After determining the constraints, we use the branch-and-bound method to solve the planning model.

After developing the ordering plan, we analyzed the forwarder loss rate and found that the same strong cyclicality exists in the loss rate. Based on this, we also used seasonal analysis to forecast the predicted loss values for the next 24 weeks. Then, we built a material transfer planning model based on the objective function of minimizing losses. The model is solved based on the principle of giving priority to the maximum delivery volume of small loss suppliers.

\subsection{Minimal Supplier Selection to Meet Demand}

By calculating the average quantity of goods supplied by each supplier in the presence of demand in the enterprise, i.e., when there is a demand for goods, we count the corresponding quantity of goods supplied, and take the average value for all statistics. Then, based on the average value of each supplier when the demand exists, we get the goods output of the supplier when the demand exists in the enterprise for the corresponding product category. Finally, we rank the suppliers based on the goods output, and select the suppliers with high output in turn until the production demand of the enterprise is satisfied. Through the calculation, we determine that at least 26 suppliers of raw materials are selected in order to possibly meet the demand of production. This is shown in the following table 4.

Table 4. 26 selected suppliers and corresponding capacity data

\begin{tabular}{ccc|ccc}
\hline Suppliers & Ranking & Capacity value & Suppliers & Ranking & Capacity value \\
\hline 201 & 1 & 2788.74 & 308 & 14 & 864.89 \\
229 & 2 & 2464.49 & 330 & 15 & 862.70 \\
140 & 3 & 2080.21 & 348 & 16 & 774.05 \\
361 & 4 & 1898.61 & 307 & 17 & 757.71 \\
108 & 5 & 1521.15 & 356 & 18 & 754.09 \\
395 & 6 & 1504.82 & 268 & 19 & 751.08 \\
282 & 7 & 1175.97 & 306 & 20 & 729.72 \\
151 & 8 & 1125.57 & 126 & 21 & 660.28 \\
275 & 9 & 1101.06 & 352 & 22 & 618.27 \\
329 & 10 & 1086.93 & 194 & 23 & 586.60 \\
340 & 11 & 1082.23 & 143 & 24 & 574.91 \\
139 & 12 & 1027.21 & 37 & 25 & 437.25 \\
131 & 13 & 868.13 & 247 & 26 & 328.11 \\
\hline
\end{tabular}

\subsection{Minimum Cost Raw Material Ordering Program}

After obtaining the raw material supply from 26 suppliers to meet the production demand, we build an ordering planning model with the objective function of minimizing the cost, and assign the most economical raw material ordering plan for each week of the next 24 weeks to the company.

(1) Total weekly order production for the next 24 weeks

The supply data has a certain periodicity, but given the randomness of the data distribution in a single sample, we cannot analyze the data patterns based on individual supplier data. Based on this, we calculate the sum of all suppliers' capacity for each week and analyze the characteristics of the overall data distribution. 


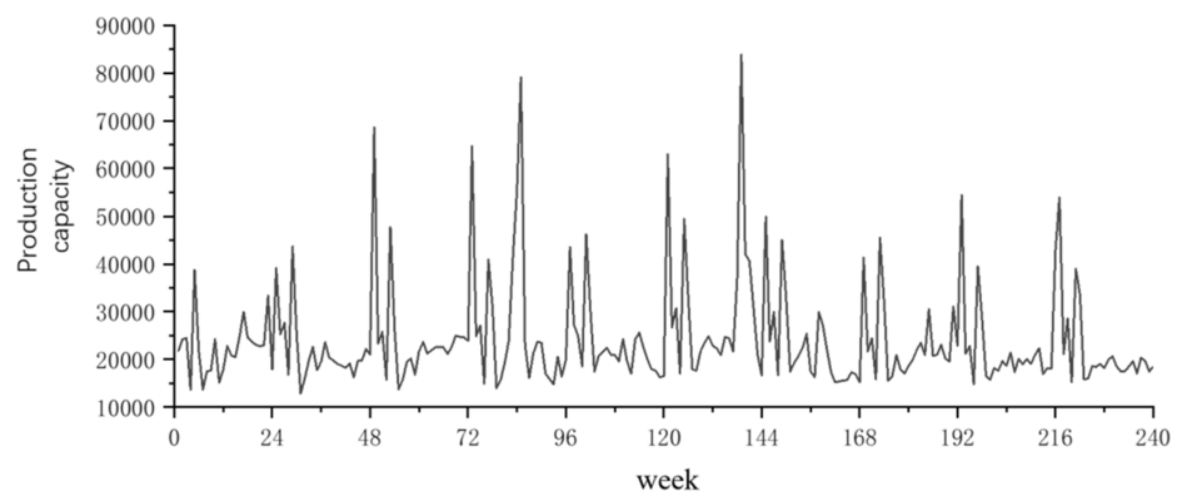

Figure 1. Total capacity line graph by week

Looking at the figure 1 we can see that the total supplier capacity fluctuates similarly every 24 weeks, indicating that there is significant seasonality in the overall supplier supply capacity. Therefore, we can use the seasonal coefficient method to predict the total weekly order quantity for the next 24 weeks based on the total capacity value of each week in the last 5 years as the reference standard for raw material ordering scheme [2][3]. The calculation steps are as follows.

Step. 1: Setting of data

Let the period be $t$, where we take to bet 24 and the number of weeks to be $T$, where we take to be 10 .

sum $_{T t}$ is the $t$ total capacity value for the first week of the $T$ cycle.

Step. 2: Overall mean value calculation

Calculate the average sum full weekly capacity values, calculated as follows.

$$
\overline{s u m}=\frac{1}{240} \sum_{T=1}^{10} \sum_{t=1}^{24} s u m_{T t}
$$

Step. 3: Calculation of the average value within the period

Calculate the average of the full weekly capacity values $\overline{s u m}_{t}$, calculated as follows.

$$
\overline{\text { sum }}_{t}=\frac{1}{10} \sum_{t=1}^{24} a_{T t}
$$

Step. 4: Periodic coefficient calculation

Calculate the period coefficient $s$, calculated as follows.

$$
s=\overline{\overline{s u m_{t}}}
$$

Step. 5: Future weekly total capacity forecast

Calculate the next weekly capacity value $\operatorname{sum}_{T+1}$, calculated as follows. 


$$
\text { sum }_{T+1}=\frac{\sum_{T=1}^{10} T \cdot \text { sum }_{T}}{\sum_{T=1}^{10} T}
$$

where, sum $_{T}=\sum_{t=1}^{24} s_{T t}$ is the total capacity value for the first $T$ week.

By solving with MATLAB software, we obtain the total weekly subscription production for the next 24 weeks, and the results are shown in the following table 5.

Table 5. Total order production forecast by week for the next 24 weeks

\begin{tabular}{|c|c|c|c|c|c|c|c|}
\hline Weekly & $\begin{array}{l}\text { Predicted } \\
\text { value }\end{array}$ & Weekly & $\begin{array}{l}\text { Predicted } \\
\text { value }\end{array}$ & Weekly & $\begin{array}{c}\text { Predicted } \\
\text { value }\end{array}$ & Weekly & $\begin{array}{c}\text { Predicted } \\
\text { value }\end{array}$ \\
\hline 1 & 49782.71 & 7 & 15442.29 & 13 & 26755.35 & 19 & 26314.35 \\
\hline 2 & 23826.59 & 8 & 17005.97 & 14 & 21943.94 & 20 & 21719.58 \\
\hline 3 & 26531.76 & 9 & 19682.87 & 15 & 21112.67 & 21 & 21303.53 \\
\hline 4 & 15850.83 & 10 & 21228.86 & 16 & 20763.04 & 22 & 21014.34 \\
\hline 5 & 43374.81 & 11 & 21678.48 & 17 & 22525.05 & 23 & 21651.68 \\
\hline 6 & 29369.68 & 12 & 22994.05 & 18 & 22400.86 & 24 & 21456.65 \\
\hline
\end{tabular}

(2) Total 24-week supply interval for each supplier

In real life, when a company develops a raw material ordering program, it evaluates the availability of individual suppliers, often choosing historical supplier trade data for evaluation. In the previous section, we used a 24 -week period as a reference criterion for ordering programs based on the overall distribution of the data. In this section, we analyze the data still based on the periodicity and totality of the data: we use 24 weeks as one cycle, calculate the total supply of materials for each cycle of the last 5 years (i.e. 10 cycles) of individual suppliers, and select the maximum and minimum values of the 10 sets of data, which constitute the supply interval, as a reference standard for ordering programs.By calculation, we obtain the total 24-week supply interval, and the results are shown in the following table 6 .

Table 6. Total 24-week supply interval endpoints by supplier

\begin{tabular}{c|cc|ccc|ccc|ccc}
\hline $\begin{array}{l}\text { Manu } \\
\text { factur } \\
\text { ers }\end{array}$ & $\begin{array}{l}\text { Left } \\
\text { Endpo } \\
\text { int }\end{array}$ & $\begin{array}{c}\text { Right } \\
\text { Endp } \\
\text { oint }\end{array}$ & $\begin{array}{c}\text { Ma } \\
\text { nuf } \\
\text { actu } \\
\text { rers }\end{array}$ & $\begin{array}{c}\text { Left } \\
\text { Endpoi } \\
\text { nt }\end{array}$ & $\begin{array}{c}\text { Right } \\
\text { Endp } \\
\text { oint }\end{array}$ & $\begin{array}{c}\text { Ma } \\
\text { nufa } \\
\text { ctur } \\
\text { ers }\end{array}$ & $\begin{array}{c}\text { Left } \\
\text { Endpoi } \\
\text { nt }\end{array}$ & $\begin{array}{c}\text { Right } \\
\text { Endp } \\
\text { oint }\end{array}$ & $\begin{array}{c}\text { Ma } \\
\text { nuf } \\
\text { actu } \\
\text { rers }\end{array}$ & $\begin{array}{c}\text { Left } \\
\text { Endp } \\
\text { oint }\end{array}$ & $\begin{array}{c}\text { Right } \\
\text { Endpo } \\
\text { int }\end{array}$ \\
\hline 37 & 132 & 14872 & 151 & 11455 & 62204 & 282 & 13477 & 20421 & 348 & 545 & 69180 \\
108 & 21555 & 26370 & 194 & 9620 & 11906 & 306 & 11757 & 14457 & 352 & 5086 & 14055 \\
126 & 6 & 33561 & 201 & 0 & 33529 & 307 & 4760 & 10193 & 356 & 7817 & 17573 \\
131 & 9679 & 16281 & 229 & 27127 & 43485 & 308 & 6543 & 19296 & 361 & 28134 & 37700 \\
139 & 10961 & 19509 & 247 & 5312 & 6570 & 329 & 14227 & 18459 & 395 & 908 & 19497 \\
140 & 15816 & 40063 & 268 & 12349 & 14777 & 330 & 6424 & 20723 & & & \\
143 & 6983 & 9837 & 275 & 14900 & 18188 & 340 & 13002 & 19832 & & &
\end{tabular}


(3) Raw material ordering planning model

We have obtained two sets of ordering scheme reference criteria, which we use as ordering scheme constraints. Also, considering that the minimum number of suppliers to satisfy the demand has been selected in 5.2.1, we do not use the firm's weekly capacity consumption as the ordering scheme constraint in this ordering scheme. Then, we build the raw material ordering planning model with the minimum cost as the objective function. The specific steps are as follows.

Step. 1: Setting of data

$x_{i j}$ is the future $j$ weekly supply of the first $i$ supplier.

sum $_{j}$ is the $j$ total future weekly order production.

$r a n g_{i}^{+}$is the right endpoint of the 24-week total supply interval for the first $i$ supplier.

$r a n g_{i}^{-}$is the left end of the 24-week total supply interval for the first $i$ supplier.

Step. 2: Establishment of the objective function

Establish the objective function at minimum cost.

$$
\min Y=\sum_{i=1}^{26} \sum_{j=1}^{24} p_{i} \cdot x_{i j}
$$

where $p_{i}$ is the price coefficient of the corresponding material type of the first $i$ supplier

Step. 3: Establishment of Constraints

We constrain the planning function based on the total ordered production and the total quantity interval.

$$
\left\{\begin{array}{l}
\sum_{i=1}^{26} x_{i j}=\operatorname{sum}_{j} \quad(j=1,2 \ldots 24) \\
\sum_{j=1}^{24} x_{i j}>\operatorname{rang}_{i}^{-} \quad(i=1,2 \ldots 26) \\
\sum_{j=1}^{24} x_{i j}<\operatorname{rang}_{i}^{+} \quad(i=1,2 \ldots 26)
\end{array}\right.
$$

(4) Improvement of ordering scheme

In the actual raw material transfer process, the transportation capacity of the forwarder is 6000 per week $m^{3}$, and the supplier often selects only one forwarder for transportation each week. Based on this actual situation, we add $m^{3}$ the constraint that each supplier's weekly supply does not exceed 6000 based on the original ordering planning model, and the constraint formula is shown below.

$$
\forall x_{i j} \leqslant 6000
$$




\subsection{Minimum Loss Of Raw Material Transfer Program}

After obtaining the minimum cost raw material ordering plan for the next 24 weeks, we develop the least lossy forwarding plan based on this ordering plan. Similarly, we need to predict the loss rate of each forwarder for the next 24 weeks and, referring to 5.2.2, we analyze whether the loss rate of forwarders is cyclical.

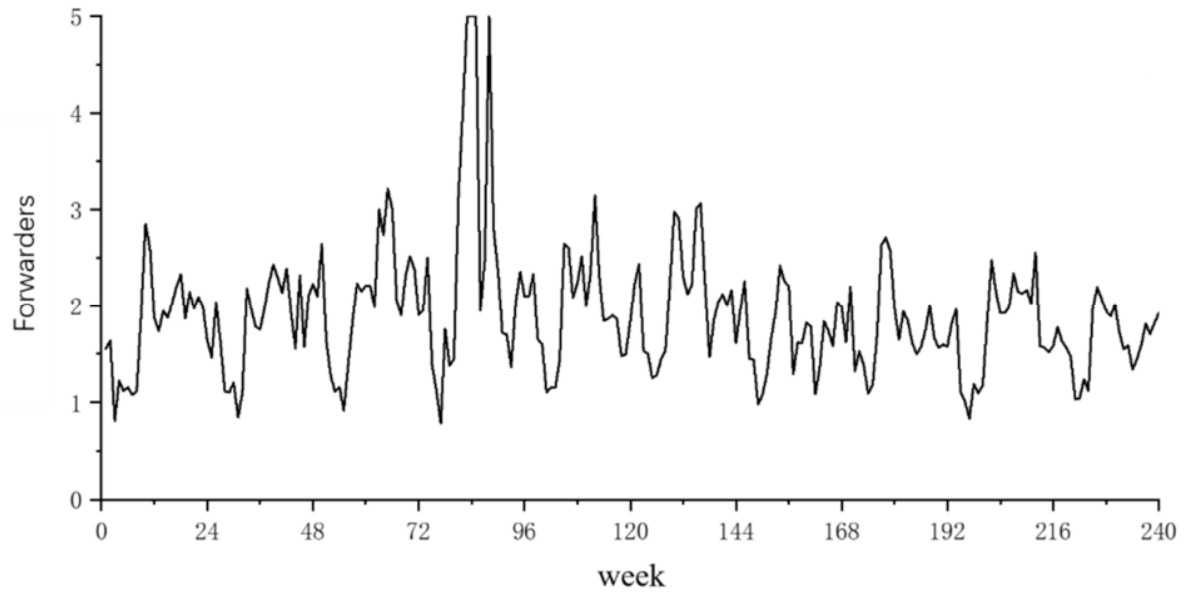

Figure 2. Folding line graph of loss rate of forwarder 1

Here we show a line chart of the forwarder 1 attrition rate (figure 2), and when compared with the total capacity line chart for each week, we can see that both are significantly cyclical and have a period of 24 . Similarly, we analyze the loss rates of the remaining forwarders and find that they are all significantly cyclical. Therefore, we again used the seasonal coefficient method to perform a time series analysis of the loss rate trends for each forwarder over the past 5 years and used MATLAB software to predict the weekly loss rate for each forwarder for the next 24 weeks (table 7).

Table 7. Transit loss rates by forwarder for the next 24 weeks

\begin{tabular}{|c|c|c|c|c|c|c|}
\hline Forwarders & Week 1 & Week 2 & Week 3 & Week 4 & $\cdots$ & Week 24 \\
\hline 1 & 1.81 & 2.11 & 1.37 & 1.29 & & 1.79 \\
\hline 2 & 0.83 & 1.07 & 0.66 & 0.97 & & 0.75 \\
\hline 3 & 0.08 & 0.05 & 0.10 & 0.03 & & 0.04 \\
\hline 4 & 0.43 & 0.37 & 0.43 & 0.24 & & 0.87 \\
\hline 5 & 0.00 & 0.06 & 0.00 & 0.00 & & 0.44 \\
\hline 6 & 0.00 & 0.04 & 0.05 & 3.83 & & 0.00 \\
\hline 7 & 1.04 & 1.00 & 1.32 & 1.36 & & 1.63 \\
\hline 8 & 0.64 & 0.00 & 0.00 & 0.00 & & 0.74 \\
\hline
\end{tabular}

After obtaining the transfer loss rate of each forwarder, we can build a material transfer planning model with minimum loss as the objective function based on the ordering scheme and the loss rate index, i.e. 


$$
\min Y=\sum_{i=1}^{26} \sum_{j=1}^{24} p_{i j}^{\prime} \cdot x_{i j}^{\prime}
$$

where $x_{i j}^{\prime}$ is the future $j$ weekly material order quantity of the company for the first $i$ supplier; and $p_{i j}^{\prime}$ is the $x_{i j}^{\prime}$ corresponding transit loss rate.

For the objective function, we analyze the problem based on the perspective of the forwarder and find that the forwarding loss must be minimized when a low-loss forwarder is preferred to deliver the goods and the forwarder is guaranteed to carry as much cargo as possible. This leads to the forwarder selection scheme (table 8).

Table 8. Table of optimal purchase and delivery options

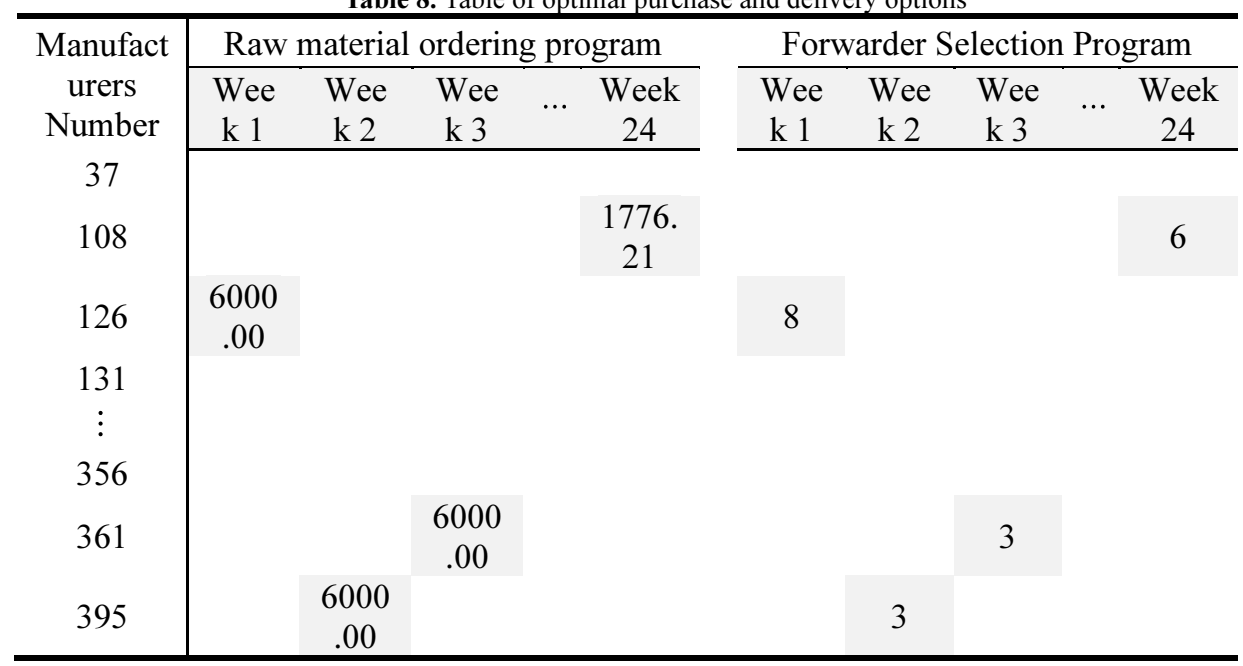

\section{Solution Selection Under Production Cost Reduction}

\subsection{Problem Analysis}

First, we define the material selection propensity index to measure the selection of raw materials of category A and $\mathrm{C}$ of the enterprise. On this basis, we establish the objective function with the largest value of the index, and form a material ordering multi-objective planning model with the cost objective function. Then, we constrain the single-week selection of $\mathrm{A}$ and $\mathrm{C}$ raw materials to provide a minimum guarantee for $\mathrm{A}$ raw materials in a single week; and considering the possible shortage of capacity brought by capacity compression, we add a lower limit requirement for weekly capacity to prevent the potential risk. After determining the new objective function and constraints, we first homogenize the objective function, then use the linear weighting method to determine the weights of each objective, transform the multi-objective planning problem into a single-objective planning problem, and solve it by the branch-and-bound method to obtain the ordering scheme. Finally, we refer to the solution process of Problem 2 and obtain the optimal transit solution based on the ordering scheme and the predicted loss rate. 


\subsection{Propensity Degree Objective Function Establishment}

In addition to raw material ordering costs, enterprises often need to bear the cost of raw material transfer and storage. Among the three types of raw material products, A and C raw materials of the same purchase price to obtain the same product conversion rate, but the same price A raw materials smaller volume, in the raw material transfer and storage process, A products cost less. Based on the need to compress costs, companies tend to get smaller costs by choosing as many Class A products as possible in the actual ordering process.

On this basis, we define the material selection tendency index to measure the selection of raw materials of category $\mathrm{A}$ and $\mathrm{C}$ of the enterprise, and establish the objective function with the maximum value of the index. Based on the intuitiveness of the problem analysis, we set $x_{i j}$ as the future $j$ week supply of the first $i$ supplier, and the tendency index $p_{j}^{\prime \prime}$ is the difference between the supply of class A suppliers and the supply of class $\mathrm{C}$ suppliers in $x_{i j}$ a single week, and then we establish the evaluation index function.

$$
\max Y=\sum_{j=1}^{24} p_{j}^{\prime \prime}
$$

\subsection{Constraint Adjustment for the Model}

Combining 5.2.2 Raw material ordering planning model and 5.3.1 Propensity index, we can obtain the following multi-objective planning model.

$$
\left\{\begin{array}{l}
\min Y_{1}=\sum_{i=1}^{26} \sum_{j=1}^{24} p_{i} \cdot x_{i j} \\
\max Y_{2}=\sum_{j=1}^{24} p_{j}^{\prime \prime}
\end{array}\right.
$$

The initial constraint equation for this objective is shown in Equation (20), and we build on this equation to make adjustments to the constraints for this model. First, we constrain the single-week selection of raw materials of categories $\mathrm{A}$ and $\mathrm{C}$ to ensure that the single-week sum of raw materials of category A is greater than the sum of raw materials of category $\mathrm{C}$, which is used to meet the cost compression needs of enterprises. Then, considering the possibility of capacity shortage after capacity compression, we cannot determine based on the data forecast that these 26 groups of suppliers will definitely be able to meet the production demand in the next 24 weeks, which suggests that equation.

This does not hold in this model, which is to say that the forecast data we obtain by satisfying the production-time calculation cannot be used as a constraint for the multiobjective planning function in the cost compression case. Instead, we add the lower capacity requirement for each week of the next 24 weeks based on the weekly capacity demand analysis to prevent the under-capacity phenomenon that occurs in capacity compression. We can obtain the following constraint. 


$$
\left\{\begin{array}{cc}
\sum_{i=1}^{26} p_{j}^{\prime \prime \prime} \cdot x_{i j} \geqslant Q_{i} & (i=1,2 \ldots 26) \\
p_{j}^{\prime \prime}>0 & (j=1,2 \ldots 24) \\
\sum_{j=1}^{24} x_{i j}>\operatorname{rang}_{i}^{-} & (i=1,2 \ldots 26) \\
\sum_{j=1}^{24} x_{i j}<\operatorname{rang}_{i}^{+} & (i=1,2 \ldots 26) \\
\forall x_{i j} \leqslant 6000 & (i=1,2 \ldots 26) \\
& (j=1,2 \ldots 24)
\end{array}\right.
$$

Where, $p_{j}^{\prime \prime \prime}$ is $x_{i j}$ the conversion ratio of the corresponding raw material product; $Q_{i}$ is the weekly demand of the enterprise in the next $i$ week; $p_{j}^{\prime \prime}$ is the propensity indicator; $\mathrm{rang}_{i}^{+}$is the right end point of the 24-week total supply interval of the first $i$ supplier; $r a n g_{i}^{-}$is the left end point of the 24-week total supply interval of the first $i$ supplier.

\subsection{Solving Multi-Objective Planning Models}

By using equation (22)(23), we have confirmed that we have obtained the specific equations of the model. Considering that the objective function $Y_{1}$ is the smallest indicator and $Y_{2}$ the largest indicator, we first homogenize the objective function, and then use the linear weighting method to determine the weights of the two indicators, here we take 0.5 for each. thus, we have transformed the multi-objective planning model into a single-objective planning model, solved it, and obtained the ordering scheme. Next, we solve the model for the optimal transit solution based on the ordering scheme and the predicted loss rate in Problem 2 (table 9).

Table 9. Technically improved scheme selection table

\begin{tabular}{|c|c|c|c|c|c|c|c|c|}
\hline $\begin{array}{l}\text { Manufact } \\
\text { urers }\end{array}$ & \multicolumn{4}{|c|}{ Raw material ordering program } & \multicolumn{4}{|c|}{ Forwarder Selection Program } \\
\hline Number & $\begin{array}{l}\text { Wee } \\
\text { k } 1\end{array}$ & $\begin{array}{l}\text { Wee } \\
\text { k } 2\end{array}$ & $\begin{array}{l}\text { Wee } \\
\text { k } 3\end{array}$ & $\begin{array}{cc}\ldots & \text { Week } \\
24\end{array}$ & $\begin{array}{l}\text { Wee } \\
\text { k } 1\end{array}$ & $\begin{array}{l}\text { Wee } \\
\mathrm{k} 2\end{array}$ & $\begin{array}{l}\text { Wee } \\
\text { k } 3\end{array}$ & $\begin{array}{cc}. . & \text { Week } \\
24\end{array}$ \\
\hline $\begin{array}{c}37 \\
108 \\
126 \\
131 \\
\vdots\end{array}$ & & & & & & & & \\
\hline 356 & & & $\begin{array}{c}3229 \\
.09\end{array}$ & $\begin{array}{c}3229 . \\
09\end{array}$ & & & 2 & 8 \\
\hline $\begin{array}{l}361 \\
395\end{array}$ & 6000 & & & & 2 & & & \\
\hline
\end{tabular}




\section{Technically Improved Solution Selection}

\subsection{Problem Analysis}

Combined with the analysis results of Problem 3, we take the maximization of enterprise interests as the core constraint of capacity enhancement, and the enterprise maximizes the capacity enhancement under the priority protection of enterprise interests. Assuming that the enterprise capacity is increased to the original capacity value $(1+\alpha)$, the capacity-related ordering scheme constraint is changed to the original value $(1+\alpha)$ times, and the minimum cost under each ordering scheme at different $\alpha$ values is determined through the ordered generation of the $\alpha$ cost capacity ratio, i.e., unit cost. Then, we compare the size of unit cost under different capacities to get the corresponding capacity value at the moment of minimum cost, and based on the constraint where this capacity value is located, the ordering and transfer scheme for the next 24 weeks.

\subsection{Analysis of Business Constraints}

The company has already gained capacity increase capability through technical modifications. Therefore, we need to assess this supply capacity capacity increase interval. First, short-term enterprise capacity growth often cannot exist an upper limit and cannot be raised without limit. Combining the actual situation of this enterprise and the results of problem three solution, we set the corporate interest as the core factor of the enterprise capacity constraint growth, and also set the initial enterprise single-week capacity increase interval as $[0,100 \%]$.

\subsection{Search for Maximum Capacity Values}

We have checked the average annual growth rates of some industries in recent years, and we have calculated the average weekly growth rate of each industry based on the annual growth rate, and we can find that the average weekly growth rate is concentrated in the range $[0.2 \%, 0.6 \%]$. Based on this, we initialize the step value $h$ to 0.1 , and the minimum value of the step value is $h 0.001$ in the iterative search process: combined with the data of the average weekly output value growth rate of the industry, the fluctuation value will be at a very low level when the step $h$ value is smaller, and at the same time, considering the simplicity of the algorithm calculation, we take the minimum value of the step $h$ value to be 0.001 .

The specific steps of the step-by-step search method are as follows in figure 3 .

Step. 1: The step size is 0.1 and the interval $[0,1]$ is selected and the unit cost is found to be the same at all points.

Step. 2: Make the step size 0.01 , select the interval $[0,0.1]$, in the 0.1 interval, the data show the trend of first up and then down, and find the minimal value point 0.08 . 
Step. 3: Make the step size 0.001, select the interval $[0.076,0.085]$, the data show scattered periodic distribution, and the minimal value point is still not 0.08 .

Step. 4: make the step size 0.001 , select the interval [0,1], find the unit cost less than 0.08 unit cost value, no smaller value found, output the minimum value point 0.08 .
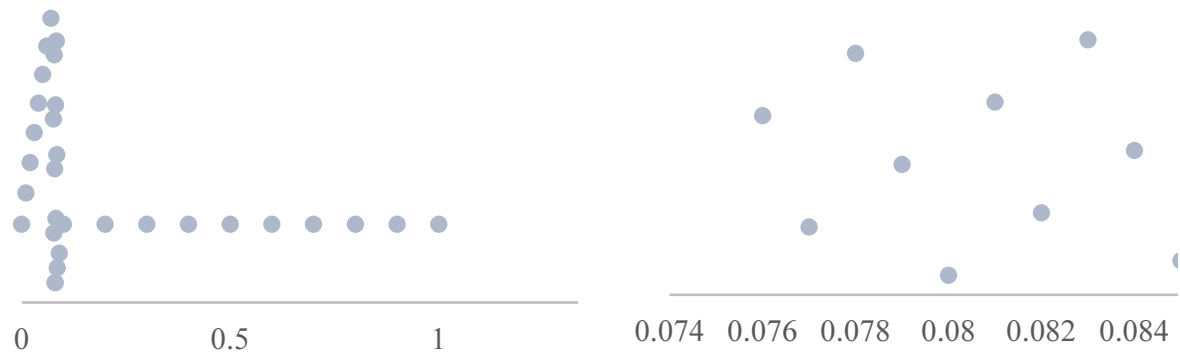

Figure 3. Scatter plot display of some areas

\subsection{Solution of the Optimal Production Value Planning Model}

After obtaining the maximum capacity growth rate of $8 \%$, we suggest adjustments to the constraints of the problem three multi-objective planning model based on the optimal production value. Considering the increase in production capacity, the total order quantity needs to be increased accordingly to meet the sustained capacity output, and we also define new upper and lower intervals for the order value based on the change in production value, and the new constraints are as follows.

$$
\left\{\begin{array}{c}
\sum_{i=1}^{26} p_{j}^{\prime \prime \prime} \cdot x_{i j} \geqslant(1+\alpha) Q_{i} \quad(i=1,2 \ldots 26) \\
p_{j}^{\prime \prime}>0 \quad(j=1,2 \ldots 24) \\
\sum_{j=1}^{24} x_{i j}>(1+\alpha) r a n g_{i}^{-} \quad(i=1,2 \ldots 26) \\
\sum_{j=1}^{24} x_{i j}<(1+\alpha) r a n g_{i}^{+} \quad(i=1,2 \ldots 26) \\
\forall x_{i j} \leqslant 6000 \quad(i=1,2 \ldots 26) \\
(j=1,2 \ldots 24)
\end{array}\right.
$$

After obtaining the new constraints, we solve the multi-objective programming function for this model with reference to Problem 3 to obtain the raw material ordering scheme and the raw material transfer scheme in turn (table 10). 
Table 10.Technically improved scheme selection table

\begin{tabular}{|c|c|c|c|c|c|c|c|c|}
\hline \multirow{2}{*}{$\begin{array}{l}\text { Manufact } \\
\text { urers }\end{array}$} & \multicolumn{4}{|c|}{ Raw material ordering program } & \multicolumn{4}{|c|}{ Forwarder Selection Program } \\
\hline & $\begin{array}{l}\text { Wee } \\
\text { k } 1\end{array}$ & $\begin{array}{l}\text { Wee } \\
\mathrm{k} 2 \\
\end{array}$ & $\begin{array}{l}\text { Wee } \\
\text { k } 3 \\
\end{array}$ & $\begin{array}{c}\text { Week } \\
24 \\
\end{array}$ & $\begin{array}{l}\text { Wee } \\
\mathrm{k} 1 \\
\end{array}$ & $\begin{array}{l}\text { Wee } \\
\mathrm{k} 2 \\
\end{array}$ & $\begin{array}{l}\text { Wee } \\
\text { k } 3 \\
\end{array}$ & $\begin{array}{c}\text { Week } \\
24 \\
\end{array}$ \\
\hline $\begin{array}{c}37 \\
108 \\
126\end{array}$ & & 6000 & & & & 5 & & \\
\hline 131 & & & & $\begin{array}{c}5583 . \\
5\end{array}$ & & & & 5 \\
\hline $\begin{array}{c}\vdots \\
356\end{array}$ & & & & & & & & \\
\hline 361 & & & $\begin{array}{c}384 . \\
72\end{array}$ & 6000 & & & 4 & 3 \\
\hline 395 & & & & & & & & \\
\hline
\end{tabular}

\section{References}

[1] YANFU ZHANG. TOPSIS Method Based on Entropy Weight for Supplier Evaluation of Power Grid Enterprise[C]. //2nd International conference on education reform and modern management: ERMM 2015, Hong Kong, China, 19-20 April 2015.:Curran Associates, Inc., 2015:334-337.

[2] SUHARTONO, B.S.S. ULAMA, A.J. ENDHARTA. Seasonal Time Series Data Forecasting by Using Neural Networks Multiscale Autoregressive Model[J]. American journal of applied sciences,2010,7(10):1372-1378.

[3] WASANA PHIWKHOM, EKKARAT BOONCHIENG. Time Series Forecasting Number of Dengue Patients using Simple Seasonal Exponential Smoothing Method[J]. Technical Report of IEICE (The Institute of Electronics, Information and Communication Engineers). Journal of Communications Society of Japan,2019,119(291):63-64. 